CHAPTER 1

\title{
Qualitative methods in health research
}

\author{
Catherine Pope, Nicholas Mays
}

Qualitative methods have much to offer those studying health care and health services. However, because these methods have traditionally been employed in the social sciences, they may be unfamiliar to health care professionals and researchers with a biomedical or natural science background. Indeed, qualitative methods may seem alien alongside the experimental and observational quantitative methods used in clinical, biological and epidemiological research.

Misunderstandings about the nature of qualitative methods and their uses have caused qualitative research to be labelled 'unscientific', difficult to replicate or as little more than anecdote, personal impression or conjecture. The first edition of this book, and the series of papers in the British Medical Journal on which the book was initially based, deliberately set out to counter this view. The growing interest in qualitative methods in health research, and their increasing acceptance in clinical and biomedical arenas, in the 10 years since the book was first published, suggest that such misunderstandings may be diminishing. The purpose of this book has therefore altered subtly. Its main aim continues to be to introduce the main qualitative methods available for the study of health and health care, and to show how qualitative research can be employed appropriately and fruitfully to answer some of the increasingly complex questions confronting researchers. In addition, the book considers the ethics of qualitative research and how to assess its quality and looks at the application of qualitative methods within different styles of research and in the emerging area of research synthesis.

MAYS: "CHAP01" — 2006/5/9 - 19:49 — PAGE 1 - \# 


\section{The link between theory and method}

Some of the earlier misunderstandings about qualitative research were compounded by some of the terminology used, which was, and may still be, unfamiliar to researchers who do not have a social science background. The terms 'qualitative research' and 'qualitative methods' are often used interchangeably, but, strictly speaking, the term research methods refer to specific research techniques used to gather data about the social world. The choice of research method is typically informed by a research strategy or a set of decisions about the research design, and by beliefs about how the social world can be studied and how the validity of social knowledge established by such research might be assessed. For many social scientists, the choice of a particular research method is also inextricably linked to a particular theoretical perspective, or set of explanatory concepts, that provide a framework for thinking about the social world and inform their research (see Box 1.1).

As a result of these different theoretical positions, qualitative research is neither unified nor well defined. There is considerable debate about what constitutes the central tenet of qualitative research. So, for example, Silverman [3] reviews four 'definitions' of qualitative research before offering his own prescriptive account of what qualitative research should be. Elsewhere, Hammersley [4] has examined the methodological ideas that underlie the distinctive Chicagoan tradition of qualitative research, with its emphasis on naturalistic methods (see below). The debate about qualitative research is such that Denzin and Lincoln [5] are forced to conclude that it is 'defined primarily by a series of essential tensions, contradictions and hesitations'. The distinctions between the various theoretical stances are frequently presented as clear-cut, but in practice the contrasts are often less apparent. Moreover, the connection

Box 1.1 Some theoretical perspectives that inform qualitative methods $[1,2]$

- Ethnography

- Symbolic interactionism

- Constructionism

- Ethnomethodology

- Phenomenology 
between research and theoretical perspective may not always be clear: sometimes the link is implicit or is simply not acknowledged. So, while many social scientists contend that research should be theoretically driven, others have suggested that the link between theory and methods is overstated. Brannen, for example, has argued that

\footnotetext{
the practice of research is a messy untidy business which rarely conforms to the models set down in methodology textbooks. In practice it is unusual, for example, for epistemology (i.e. the specific theory of the nature of knowledge adopted by the researcher) to be the sole determinant of method... There is no necessary or one-to-one correspondence between epistemology and methods [6: 3,15].
}

She suggests that the choice of method and how it is used are as likely to be informed by the research question or pragmatic or technical considerations as by the researcher's theoretical stance (though others would disagree). This may be particularly the case in health services research because of its applied nature: research here tends to be geared towards specific practical problems or issues and this, rather than theoretical leanings, may determine the methods employed.

\section{So what is qualitative research?}

Qualitative research is often defined by reference to quantitative research. Indeed, the articles on which the first edition of this book was based were commissioned, not as a series about qualitative research, but as a series on 'non-quantitative methods'. An unfortunate corollary of this way of defining qualitative research is the inference that because qualitative research does not seek to quantify or enumerate, it does not 'measure'. It is worth noting that it is both feasible and legitimate to analyse certain types of qualitative data quantitatively (see Chapter 7). Whilst it is true that qualitative research generally deals with talk or words rather than numbers, this does not mean that it is devoid of measurement, or that it cannot be used to explain social phenomena.

Measurement in qualitative research is usually concerned with taxonomy or classification. Qualitative research answers questions such as, 'what is $\mathrm{X}$, and how does $\mathrm{X}$ vary in different circumstances, and why?' rather than 'how big is X or how many X's are there?'

MAYS: "CHAP01" - 2006/5/9 - 19:49 - PAGE 3 - \#3 
It is concerned with the meanings people attach to their experiences of the social world and how they make sense of that world. It therefore tries to interpret social phenomena (interactions, behaviours, etc.) in terms of the meanings people bring to them; because of this it is often referred to as interpretative research. This approach means that the researcher frequently has to question common sense assumptions or ideas that are taken for granted. Bauman, talking about sociology in general, refers to this as 'defamiliarising' [7] and this is just what qualitative research tries to do. Rather than simply accepting the concepts and explanations used in everyday life, qualitative research asks fundamental and searching questions about the nature of social phenomena. So, for example, instead of counting the number of suicides, which presumes that we already agree on the nature of suicide, the researcher may well start by asking, 'what is suicide and how is it defined in this society?' and go on to show that it is socially constructed by the activities of coroners, legal experts, health professionals and individuals, so that definitions of suicide vary considerably between different countries, different cultures and religious groups, and across time [8].

A second distinguishing feature of qualitative research, and one of its key strengths, is that it studies people in their natural settings rather than in artificial or experimental ones. Kirk and Miller define qualitative research as a 'particular tradition in social science that fundamentally depends on watching people in their own territory, and interacting with them in their own language, on their own terms' [9: 9]. This is referred to as naturalism - hence the term naturalistic methods that is sometimes used to denote the approach used in much, but not all, qualitative research.

Another feature of qualitative research (which some authors emphasise) is that it often employs several different qualitative methods. Watching people in their own territory can thus entail observing, joining in (participantobservation), talking to people (interviews, focus groups and informal chatting) and reading what they have written. In the health care context, a range of qualitative research methods has been employed to tackle important questions about social phenomena, ranging from complex human behaviours such as patients' compliance with treatment [10], and decision making by health care professionals [11], through to the organisation of the hospital clinic [12] or of the health system as a whole [13,14].

Qualitative research, thus defined, appears very different from quantitative research. Much is made of the differences between the

MAYS: "CHAP01" — 2006/5/9 - 19:49 — PAGE 4 - \#4 
two. The so-called qualitative-quantitative divide is often reinforced by highlighting a corresponding split in the social sciences between social theories concerned with delineating social structure and those concerned with understanding social action or meaning $[15,16]$. The crude alignment of qualitative research with 'action' or interpretive approaches and quantitative research with 'structural' or positivist ones has meant that researchers on either side have tended to become locked into adversarial positions, ignorant of each other's work. The differences between qualitative and quantitative research are, as a result, frequently overstated, and this has helped to perpetuate the misunderstanding of qualitative methods within such fields as health services research [17]. However, there is a growing recognition within sociology that the qualitative-quantitative distinction may not be helpful or even accurate $[18,19]$. In the context of health and health services research qualitative and quantitative methods are increasingly being used together in mixed method approaches (see Chapter 9 for more on this) [20].

\section{The uses of qualitative research}

Quantitative and qualitative approaches can complement each other. One simple way in which this can be achieved is by using qualitative research as the preliminary to quantitative research. This model is likely to be the most familiar to those engaged in health and health services research. For example, qualitative research can classify phenomena, or answer the 'what is X?' question, which necessarily precedes the process of enumeration of X's. As health care deals with people and people are, on the whole, more complex than the subjects of the natural sciences, there is a whole set of such questions about human interaction, and how people interpret interaction, to which health professionals may need answers before attempting to quantify behaviours or events. At their most basic, qualitative research techniques can be used simply to discover the most comprehensible terms or words in common use to include in a subsequent survey questionnaire. An excellent example of this can be found in the preliminary work undertaken for the British national survey of sexual attitudes and lifestyles [21]. In this case, face-to-face interviews were used to uncover popular ambiguities and misunderstandings in the use of a number of terms such as 'vaginal sex', 'oral sex', 'penetrative sex' and 'heterosexual'. This qualitative work had enormous value in informing the development

MAYS: "CHAP01" — 2006/5/9 - 19:49 — PAGE 5 - \#5 
of the subsequent survey questionnaire, and in ensuring the validity of the data obtained because the language in the questionnaire was clear and could be widely understood.

Qualitative research is not only useful as the first stage of quantitative research. It also has a role to play in 'validating' quantitative research or in providing a different perspective on the same social phenomena. Sometimes it can force a major reinterpretation of quantitative data. For example, one anthropological study using qualitative methods uncovered the severe limitations of previous surveys: Stone and Campbell found that cultural traditions and unfamiliarity with questionnaires had led Nepalese villagers to feign ignorance of abortion and family planning services, and to underreport their use of contraception and abortion when responding to surveys [22]. More often, the insights provided by qualitative research help to interpret or understand quantitative data more fully. Bloor's work on the surgical decision making process built on an epidemiological study of the widespread variations in rates of common surgical procedures (see Box 1.2) and helped to unpack the reasons why these variations occurred [11]. Elsewhere, Morgan and Watkin's research on cultural beliefs about hypertension has helped to explain why rates of compliance with prescribed medications vary significantly amongst and between white and Afro-Caribbean patients [10].

As well as complementing quantitative work, qualitative research may be used quite independently to uncover social processes, or access areas of social life that are not open or amenable to quantitative research. This type of 'stand alone' qualitative research is increasingly being used in studies of health service organisation and policy. It has been used to considerable effect in evaluating organisational reforms and changes to health service provision from the viewpoint of patients, health professionals and managers [14,23]. This type of research has also been useful in examining how data about health and health care are shaped by the social processes that produce them - from waiting lists [24] to death certificates [25] and AIDS registrations [26].

\section{Methods used in qualitative research}

Qualitative research explores people's subjective understandings of their everyday lives. Although the different social science disciplines use qualitative methods in slightly different ways, broadly speaking,

MAYS: "CHAP01" — 2006/5/9 - 19:49 — PAGE 6 - \#6 
Box 1.2 Two-stage investigation of the association between differences in geographic incidence of operations on the tonsils and adenoids and local differences in specialists' clinical practices [27]

\section{Epidemiological study - documenting variations}

Analysis of 12 months' routine data on referral, acceptance, and operation rates for new patients under 15 years in two Scottish regions known to have significantly different 10 -year operation rates for tonsils and adenoids.

Found significant differences between similar areas within regions in referral, acceptance, and operation rates that were not explained by disease incidence.

Operation rates influenced, in order of importance, by:

- Differences between specialists in propensity to list for operations

- Differences between GPs in propensity to refer

- Differences between areas in symptomatic mix of referrals.

II Sociological study - explaining how and why variations come about. Observation of assessment routines undertaken in outpatient departments by six consultants in each region on a total of $\mathbf{4 9 3}$ patients under 15 years

Found considerable variation between specialists in their assessment practices (search procedures and decision rules), which led to differences in disposals, which in turn created local variations in surgical incidence.

'High operators' tended to view a broad spectrum of clinical signs as important and tended to assert the importance of examination findings over the child's history; 'low operators' gave the examination less weight in deciding on disposal and tended to judge a narrower range of clinical features as indicating the need to operate.

the methods used in qualitative research include direct observation, interviews, the analysis of texts or documents and the analysis of recorded speech or behaviour using audio or video tapes. Data collected by these methods may be used differently (e.g. semiotics and psychotherapy both use video and audio-taped material, but their analytical approaches are distinctive), but there is a common focus

MAYS: "CHAP01" — 2006/5/9 — 19:49 — PAGE 7 — \# 
on talk and action rather than numbers. On one level, these 'qualitative methods' are used every day by human beings to make sense of the world - we watch what is going on, ask questions of each other and try to comprehend the social world we live in. The key difference between these and the qualitative methods employed in social science is that the latter are explicit and systematic. Qualitative research, therefore, involves the application of logical, planned and thorough methods of collecting data, and careful, thoughtful and, above all, rigorous analysis. As several recent commentators have pointed out, this means that qualitative research requires considerable skill on the part of the researcher $[28,29]$. Perhaps more than some quantitative research techniques, qualitative research needs experienced researchers. One of the problems arising from the rapid expansion of qualitative methods into medical and health fields is that the necessary skill and experience are sometimes lacking.

This book focuses on ways of doing qualitative research which, in essence, rely on conversation (talking) and/or observation (watching). Qualitative researchers use conversation, in the form of interviews, to collect data about people's views and experiences. Interviews can be individual or focus groups (group interviews) (Chapters 2 and 3). In addition, talk or conversation can be analysed in much greater detail using an approach called conversation analysis (Chapter 5). Observation (Chapter 4) is used to collect information about behaviour and events, but may also involve collecting examples of how people talk (e.g. their attitudes to, and understandings of, issues). The book concentrates on these methods because they appear to be the most widely used in health and health services settings. We have neglected documentary methods and forms of textual analysis [30], which have been used in the health field, for example, to describe mass media reporting of AIDS [31], to ascertain the public and professional attitudes to tranquilliser use portrayed by the popular press [32], and to study diaries kept by rural dwellers during the UK foot and mouth disease outbreak of 2001 [33].

The book is introductory and aims to show how these methods can be employed in health research. It seeks to provide clear examples of these methods and to indicate some of the benefits and common pitfalls in their use. It is not a substitute for seeking the advice of a skilled, experienced researcher, nor is it an exhaustive manual for qualitative research. In addition to the references, which provide a route to more detailed material on each of the topics covered, each

MAYS: "CHAP01" — 2006/5/9 - 19:49 — PAGE 8 - \#8 
chapter ends with a short guide to further reading that would be well worth doing before planning a study or going into the field. Chapter 6 provides an introduction to some of the key ethical issues confronting qualitative research, and again this is not intended as exhaustive, but rather to illustrate some of the special dilemmas encountered when doing qualitative research. Chapter 7 outlines how qualitative data are analysed and includes a description of the main software packages currently available to assist this process. Chapter 8 examines the issue of 'quality' in qualitative research and how it may be assessed and assured. Chapters 9-12 explore some of the ways in which qualitative methods are applied in health research. We have chosen examples (mixed methods, case studies, action research, and consensus development,) where qualitative methods are currently used in health and health services research simply to demonstrate how qualitative methods may be used. It is not our intention to argue that these approaches are synonymous with the whole of qualitative research, but rather to indicate that qualitative methods have fruitfully been employed in these ways. The final chapter introduces research synthesis and looks at the ways in which qualitative methods are being employed to integrate research evidence in health and health care.

\section{Further reading}

Green J \& Thorogood N. Qualitative Methods for Health Research. SAGE, London, 2004.

Murphy E, Dingwall R, Greatbatch D, Parker S \& Watson P. Qualitative research methods in health technology assessment: a review of the literature. Health Technology Assessment 1998; 2(16) (see section 1).

\section{References}

1. Marshall C \& Rossman G. Designing Qualitative Research. SAGE, London, 1989.

2. Feldman MS. Strategies for Interpreting Qualitative Data. Qualitative Research Methods Series, No 33. SAGE, Thousand Oaks, CA, 1995.

3. Silverman D. Interpreting Qualitative Data: Methods for Analysing Talk, Text and Interaction. SAGE, London, 1993.

4. Hammersley M. The Dilemma of Qualitative Method: Herbert Blumer and The Chicago Tradition. Routledge, London, 1989.

5. Denzin NK \& Lincoln YS, eds. Handbook of Qualitative Research. SAGE, London, 1994: ix.

MAYS: "CHAP01" — 2006/5/9 - 19:49 — PAGE 9 — \#9 
6. Brannen J, ed. Mixing Methods: Qualitative and Quantitative Research. Avebury, Aldershot, 1992: 3, 15.

7. Bauman Z. Thinking Sociologically. Blackwell, Oxford, 1990.

8. Douglas J. The Social Meanings of Suicide. Princeton University Press, Princeton, NJ, 1967.

9. Kirk J \& Miller M. Reliability and Validity in Qualitative Research. Qualitative Research Methods Series, No 1. SAGE, London, 1986: 9.

10. Morgan M \& Watkins C. Managing hypertension: beliefs and responses to medication among cultural groups. Sociology of Health and Illness 1988; 10: $561-578$.

11. Bloor M. Bishop Berkeley and the adenotonsillectomy enigma: an exploration of the social construction of medical disposals. Sociology 1976; 10: 43-61.

12. Strong PM. The Ceremonial Order of the Clinic. Routledge, London, 1979.

13. Strong PM \& Robinson J. The NHS: Under New Management. Open University Press, Milton Keynes, 1990.

14. Pollitt C, Harrison S, Hunter D et al. General management in the NHS: the initial impact, 1983-88. Public Administration 1991; 69: 61-83.

15. Mechanic D. Medical sociology: some tensions among theory, method and substance. Journal of Health and Social Behavior 1989; 30: 147-160.

16. Pearlin L. Structure and meaning in medical sociology. Journal of Health and Social Behavior 1992; 33: 1-9.

17. Pope C \& Mays N. Opening the black box: an encounter in the corridors of health services research. British Medical Journal 1990; 306: 315-318.

18. Abell P. Methodological achievements in sociology over the past few decades with special reference to the interplay of qualitative and quantitative methods. In: Bryant C \& Becker H, eds. What Has Sociology Achieved? Macmillan, London, 1990.

19. Hammersley M. Deconstructing the qualitative-quantitative divide. In: Brannen J, ed. Mixing Methods: Qualitative and Quantitative Research. Avebury, Aldershot, 1992.

20. Barbour R. The case for combining qualitative and quantitative approaches in health services research. Journal of Health Services Research and Policy 1999; 4: 39-43.

21. Wellings K, Field J, Johnson A et al. Sexual Behaviour in Britain: The National Survey of Sexual Attitudes and Lifestyles. Penguin, Harmondsworth, 1994.

22. Stone L \& Campbell JG. The use and misuse of surveys in international development: an experiment from Nepal. Human Organisation 1986; 43: 27-37.

23. Packwood T, Keen J \& Buxton M. Hospitals in Transition: The Resource Management Experiment. Open University Press, Milton Keynes, 1991. 
24. Pope C. Trouble in store: some thoughts on the management of waiting lists. Sociology of Health and Illness 1991; 13: 191-211.

25. Prior L \& Bloor M. Why people die: social representations of death and its causes. Science As Culture 1993; 3: 346-374.

26. Bloor M, Goldberg D \& Emslie J. Ethnostatistics and the AIDS epidemic. British Journal of Sociology 1991; 42: 131-137.

27. Bloor MJ, Venters GA \& Samphier ML. Geographical variation in the incidence of operations on the tonsils and adenoids: an epidemiological and sociological investigation. Journal of Laryngol and Otology 1976; 92 : 791-801, 883-895.

28. Malterud K. Shared understanding of the qualitative research process: guidelines for the medical researcher. Family Practice 1993; 10: 201-206.

29. Dingwall R, Murphy E, Watson $P$ et al. Catching goldfish: quality in qualitative research. Journal of Health Services Research and Policy 1998; 3: 167-172.

30. Plummer K. Documents of Life: An Introduction to Problems and Literature of a Humanistic Method. Allen and Unwin, London, 1983.

31. Kitzinger J \& Miller D. "African AIDS": the media an audience believes. In: Aggleton P, Davies P \& Hart G, eds. AIDS: Rights, Risk and Reason. Falmer Press, London, 1992.

32. Gabe J, Gustaffson U \& Bury M. Mediating illness: newspaper coverage of tranquilliser dependence. Sociology of Health and Illness 1991; 13 332-353.

33. Mort M, Convery I, Baxter J et al. Psychosocial effects of the 2001 UK foot and mouth disease epidemic in a rural population: qualitative diary based study. British Medical Journal 2005; 331: 1234-1238.

MAYS: "CHAP01" — 2006/5/9 — 19:49 — PAGE 11 — \#11 